\title{
Effect on the Mechanical Properties of Grey Cast Iron with Variation of Molybdenum and AS - Cast Alloying Elements
}

\author{
Sujith Bobba ${ }^{1, *}$, Mukkollu Sambasiva Rao ${ }^{2}$, B. Harish Babu ${ }^{1}$, Z. Leman ${ }^{3}$ \\ ${ }^{1}$ Department of Applied Engineering, Vignan's Foundation for Science Technology \& Research (VFSTR), Guntur, AP, India \\ ${ }^{2}$ National Institute of Foundry \& Forge Technology, Ranchi, Jharkhand, India \\ ${ }^{3}$ Department of Mechanical and Manufacturing Engineering, Faculty of Engineering, Universiti Putra Malaysia, 43400 Serdang, \\ Malaysia
}

Received September 8, 2020; Revised October 15, 2020; Accepted November 11, 2020

\section{Cite This Paper in the following Citation Styles}

(a): [1] Sujith Bobba, Mukkollu Sambasiva Rao, B. Harish Babu, Z. Leman, "Effect on the Mechanical Properties of Grey Cast Iron with Variation of Molybdenum and AS - Cast Alloying Elements," Universal Journal of Mechanical Engineering, Vol. 8, No. 6, pp. 298 - 304, 2020. DOI: 10.13189/ujme.2020.080602.

(b): Sujith Bobba, Mukkollu Sambasiva Rao, B. Harish Babu, Z. Leman (2020). Effect on the Mechanical Properties of Grey Cast Iron with Variation of Molybdenum and AS - Cast Alloying Elements. Universal Journal of Mechanical Engineering, 8(6), 298 - 304. DOI: 10.13189/ujme.2020.080602.

Copyright $\odot 2020$ by authors, all rights reserved. Authors agree that this article remains permanently open access under the terms of the Creative Commons Attribution License 4.0 International License

\begin{abstract}
Metal casting is a predominant manufacturing advancement for adeptly fabricating components with complicated shapes. Many of the industrial castings produced are made from steel and iron alloys with attractive properties and less production cost. In this research work, the effect of molybdenum addition to class 30 type grey cast iron for the production of high performance cast iron (HPCI) has been carried out. Molybdenum inclusion not only refines the majority of graphite flakes but also increases the length of a small fraction of graphite flakes and improves the thermal conductivity by a percentage up to $2.2 \%$ fixed as per the research conducted, while excessive molybdenum insertion not only induces precipitation and solution reinforcement but it will also enhance the ultimate tensile strength (UTS) and hardness. According to research conducted, it was proved that molybdenum inclusion of $120 \mathrm{gm}$ showed a functional way to spread HPCI with enhancing mechanical and thermal properties in grey cast iron when compared to other percentages of molybdenum used and also the average difference in the percentage of hardness in each type of molybdenum sample is about 5 to $10 \%$. Finally, after the tests, it was also predicted that the molybdenum's hardenability property was beneficial for white cast iron production which will rise the wear resistance property.
\end{abstract}

Keywords Molybdenum, Grey Cast Iron, High Performance Cast Iron (HPCI), Ultimate Tensile Strength (UTS), Hardness

\section{Introduction}

Due to superior production and reasonable cost, grey cast iron has been extensively used as one of the important materials for automobile components such as engine blocks and flywheel. These components are predominantly made of grey cast iron in the view of the fact it has the utmost mixture of thermal and mechanical properties. Nevertheless, for instantaneous overloading, it is required that typical grey cast iron can't meet the production requirements. Thus it is necessary to develop high performance cast iron (HPCI) with improved mechanical properties while maintaining high thermal conductivity to restore the elevated cost of ductile iron in the application of automobile components [1]. The metallurgy of cast iron is influenced by chemical composition, cooling rate, liquid treatment, and heat treatment. Strength and hardness, resistance to heat and oxidation, corrosion, electrical and magnetic characteristic, 
and section sensitivity is changed by alloying with certain elements that extend the applications of gray iron into fields where costlier material has traditionally been used. Also, unalloyed gray iron is replaced by alloyed gray iron to meet the increasing demands and to provide increased safety factors.

In order to upgrade gray cast iron service performance, some investigators worked on to develop molybdenum based grey cast iron alloys with modified chemical compositions to rise their wear resistance and other significant properties. Molybdenum [2, 3] is generally a carbide stabilizing group. Molybdenum is utilized for reinforcement and hardening of iron during the austenite transformation where fine pearlite is transfer to bainite. It is commonly included in gray cast iron for upgrading pearlite. Molybdenum is normally added as Ferromolybdenum comprising of 60 to $70 \%$ Molybdenum. $[4,5]$

According to the study done on molybdenum induced gray cast iron alloys [6-10], the alloys exhibited greater hardness and tensile strength than familiar pearlite grades of gray cast iron. Janowiak and Gundlach [11] examined on higher room temperatures influence on the mechanical properties of gray iron alloyed with copper-molybdenum. Hugrynen et al. [12] identified an improvement in mechanical properties of gray cast iron when induced with copper and molybdenum on different composition basis. The mechanical properties such as corrosion, wear resistance, toughness and tensile strength have improved as the composition percentage of the copper and molybdenum increased. As a consequence, a ferreting effect on the cast iron can be obtained by molybdenum concentrations of $0.2-0.3 \%$. This becomes apparent by the high values of elongation and strength. In addition, the elevated-temperature resistance is increased by molybdenum which decreases the danger of material deformation at temperature changes. Higher molybdenum concentration and long cooling times (thick section castings) achieve carbide formation and with it a loss of toughness. These molybdenum-containing composite carbides are very stable and cannot be dissolved completely by heat treatment. In some cases where for improved automobile engines, immediate overloading is required and conventional grey cast iron is unable to meet the performance specifications [13]. According to Krause [14], the inclusion of $1.00 \%$ each, silicon decreases the quantity of the carbon in the eutectic to $0.34 \%$. The most usual scale for manganese in grey iron is from $0.54 \%$ to $0.76 \%$. expanding the manganese percent will tend to assist the development of pearlite during cooling by its critical intervals. When collating to ferritic, pearlitic, or martensitic structures, ferrite show doubles the strength for a given level of ductility formed by conventional heat treatment [15].

Thus, according to the research performed it is necessary to develop high-performance cast iron (HPCI) with improved mechanical properties with sustaining high thermal conductivity to replace high-cost ductile iron in the application of automobile flywheel.

\section{Experimental Details}

\subsection{Charge Material}

Charge material is used pig iron, steel scrap and foundry yield of grey cast iron. The carbon corresponding value to melt was planned in the range of 3.8 to $4.2 \%$. Subsequent composition of the charge medium was considered to gain above carbon corresponding value.

The utmost base composition required is $3.1 \% \mathrm{C}$, $2.24 \% \mathrm{Si}, 0.54 \% \mathrm{Mnin}$ the shape of wedge is used for expanding the silicon percentage in the base iron for inoculation as shown in the Table 1 and Table 2.

Table 1. Final base composition used

\begin{tabular}{|c|c|c|c|}
\hline $\begin{array}{c}\text { Charge } \\
\text { Material }\end{array}$ & \% C & \%Si & \% Mn \\
\hline Pig iron & 3.7 & 1.57 & 0.60 \\
\hline Mild steel & 0.2 & 0.15 & $0.2-0.6$ \\
\hline
\end{tabular}

Table 2. Different alloying sample composition

\begin{tabular}{|c|c|c|c|c|c|c|c|}
\hline Sample & $\% \mathrm{C}$ & $\% \mathrm{Si}$ & $\% \mathrm{Mn}$ & $\% \mathrm{~S}$ & $\% \mathrm{P}$ & $\% \mathrm{Mo}$ & $\% \mathrm{Fe}$ \\
\hline Grey iron (Class 30) & 3.18 & 2.25 & 0.55 & 0.05 & 0.11 & 0 & \multirow{6}{*}{ REST } \\
\hline $0.02 \% \mathrm{Mo}(4 \mathrm{gm})$ & 3.18 & 2.25 & 0.55 & 0.05 & 0.11 & 0.02 & \\
\hline $0.15 \% \mathrm{Mo}(30 \mathrm{gm})$ & 3.18 & 2.24 & 0.55 & 0.05 & 0.11 & 0.15 & \\
\hline $0.27 \% \mathrm{Mo}(60 \mathrm{gm})$ & 3.17 & 2.24 & 0.55 & 0.05 & 0.11 & 0.29 & \\
\hline $0.55 \% \mathrm{Mo}(120 \mathrm{gm})$ & 3.15 & 2.23 & 0.54 & 0.05 & 0.11 & 0.59 & \\
\hline $0.75 \% \mathrm{Mo}(150 \mathrm{gm})$ & 3.15 & 2.22 & 0.54 & 0.05 & 0.11 & 0.74 & \\
\hline
\end{tabular}




\section{Experimental Procedures}

\subsection{Sand Preparation and Moulding}

First of all, four cylindrical wooden pattern were prepared as per required dimension with proper allowances. Green sand is used for molding and mould were rammed by hand properly. For making mould, the sand consisting of high silica sand, bentonite $(2 \%)$ and dust from the foundry workshop of the institute were used. Mulling was carried out in a muller of $150 \mathrm{~kg}$ capacity in the foundry workshop. $4 \%$ water were added during mulling. All the moulds were prepared one day before of the casting. Shop stone powder was applied to the pattern for clean stripping and to act as mould coating. Green sand was used for preparing moulds for test bar. Melting is done in core less type induction furnace. The mould cavity is filled with molten iron to form the casting. In foundry, generally remelting is done with little refining wherever possible. Scraps are sufficient amounts of different elements necessary for alloy composition are added either as virgin metal or as master alloy. Type of melting equipment used by a particular foundry depends on a number of factors including the kind of iron produced, the demand for molten iron as determined by variations in mould production, and the electric power, fuels and melting stock.

Charging material must be free from rust, oil or grease and manganese material. The scrap be segregated composition wise or grade wise of the pig iron according to the physical size. The loading sequence of charge be such that dense packing is obtained. Hearth of the induction furnace was charged with pig iron $10 \mathrm{~kg}$, mild steel of $2.5 \mathrm{~kg}$, graphite $30 \mathrm{gm}$ and $170 \mathrm{gm}$ of ferrosilicon to raise the percentage of silica in base iron for melting cast iron, we use core less induction furnace. Capacity of the furnace is $100 \mathrm{~kg}$. The advantage of induction heating is that the heat is generated within the furnace charge itself rather than applied by external source. During later stages when charging material get completely converted into molten metal, was observed from time to time. The melt was inoculated with $\mathrm{Fe}-\mathrm{Si}$ containing $55 \% \mathrm{Si}$ and its size was less then $3 \mathrm{~mm}$. The amount of inoculants used were $0.3 \%$ of the molten metal.

\subsection{Ladle Preheating, Pouring and Casting}

The ladle was preheated before transferring the molten metal from the furnace to mold and to reduce the temperature loss of liquid metal, moisture absorption of the ladle which was preheated. Preheated of the ladle was carried out with the help of coke pieces up to about $1000^{\circ} \mathrm{C}$. A blower was used to increase the efficiency of coke combustion and better heat utilization. Before pouring, the different amount of inoculants are put in the four tensile bar molds. After the molten metal was superheated, the required quantity of liquid metal was transferred to the preheated ladle. The molten metal was poured in the four tensile bar molds and finally, after the metal has solidified and cooled in the sand mold, the castings were knocked out by breaking the mold.

\subsection{Specimen Preparation}

Thirty moulds were prepared in nine molding boxes as shown in Figure 1, which are clamped properly to avoid a liquid metal leak. Six specimens were prepared from the tensile test bar casting. Every test bar contains the same amount of inoculants and different amounts of alloying. Cylindrical specimens were cut from the test bar for chemical analysis and the specimens were used for tensile tests, hardness tests and metallography. The dimension of the tensile test bar specimen was shown in Figure 2.

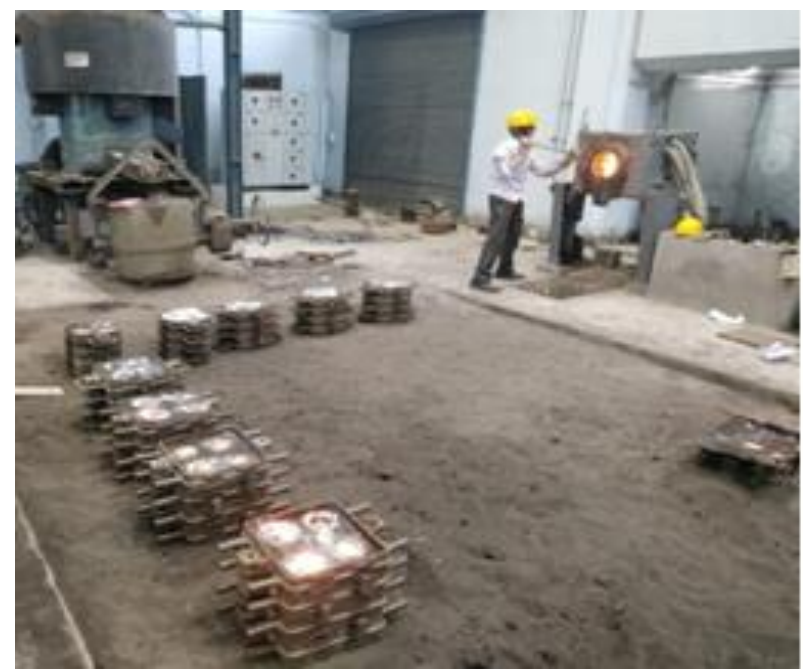

Figure 1. Representation of the process after pouring metals into the cast

According to the ASTM Standards the ratio of gauge diameter to gauge length should be 1:5. Hence turning was done to get the required specifications shown in Table 3 below.

Table 3. Specifications of the specimen used

\begin{tabular}{|c|c|c|}
\hline S.No & Parameter & Value \\
\hline 1 & Gauge length & $60 \mathrm{~mm}$ \\
\hline 2 & Gauge diameter & $12 \mathrm{~mm}$ \\
\hline 3 & Total length & $130 \mathrm{~mm}$ \\
\hline 4 & Grip diameter & $18 \mathrm{~mm}$ \\
\hline
\end{tabular}

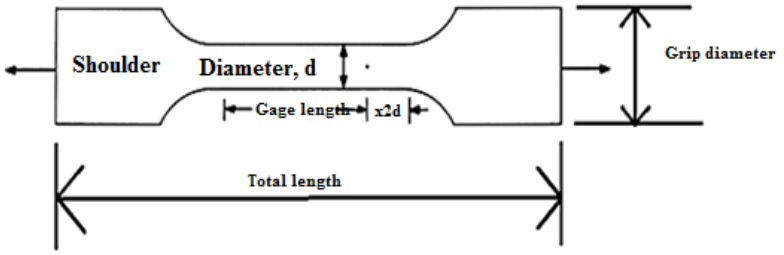

Figure 2. Diagrammatic view of the specimen with different parameters 

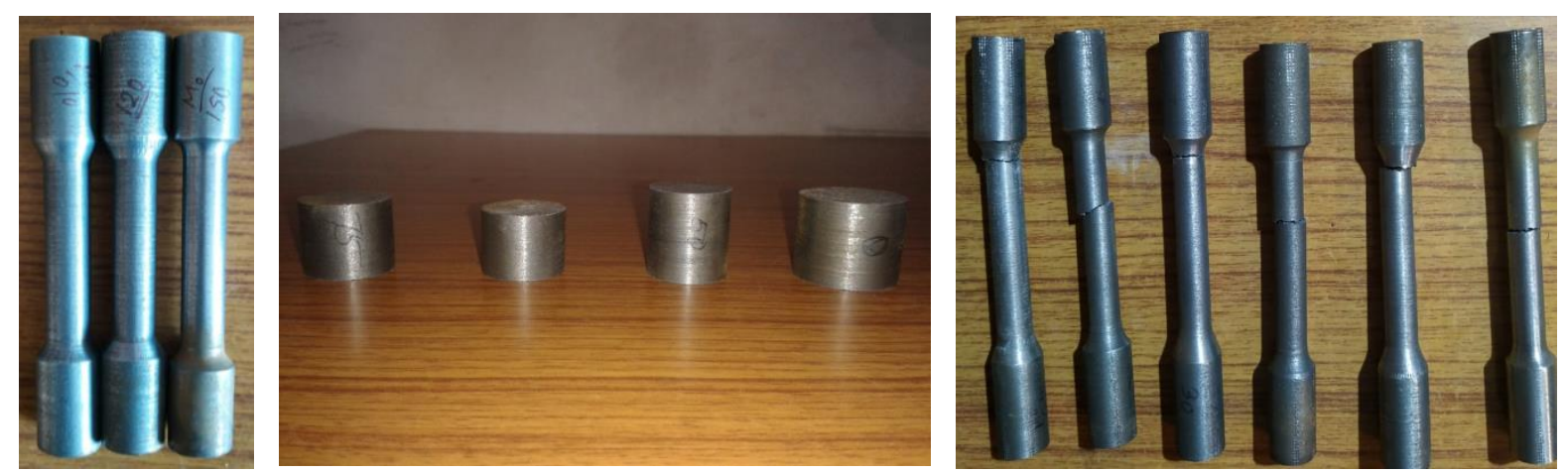

Figure 3. Systematic representation of break down tensile test bars and grinded test piece for hardness test

\section{Mechanical Testing}

Mechanical tests plan to be carried out in the present investigation are tensile strength, hardness and percentage elongation. However, percentage elongation could not be measured as the material was brittle.

\subsection{Tensile Test}

Tensile strength of the specimen was measured on universal testing machine as shown in Figure 4 which has a maximum capacity of 10 tons by weight.

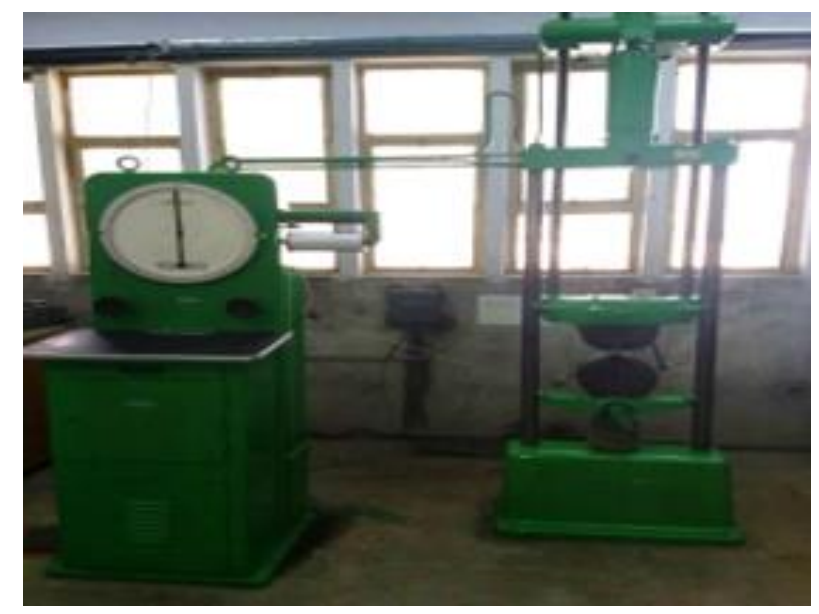

Figure 4. Universal tensile machine UTM used for mechanical tests on the specimens

Cast test bars machined according to IS 2078-1979[16]. Tensile strength was carried out on universal testing machine. In foundry industry the test bar results cannot be used to give the strength of the casting itself here section thickness and cooling rates may vary appreciably.

Tensile test specimen was fixed between the two jaws (i.e upper jaw and lower jaw). Lower jaw was manually operated and upper jaw was fixed in the machine. The specimen was held by upper jaw and moving the lower jaw. It was fixed between jaws. The pressure applied was hydraulic. Due to pressure, upper jaw moves up which results in the application of tensile load due to which specimen was broken into two pieces. Reading of the load and cross section of the specimen was noted. The tensile strength was calculated as follows:

$$
\text { Tensile strength }=\frac{\text { Tensile load }(\mathrm{kg})}{\text { cross sectional area }\left(\mathrm{mm}^{2}\right)}
$$

\subsection{Hardness Test}

Even though hardness testing is apprehendingfor acceptance in the current situation, the property of hardness is extremely complex one and standardization of methods of testing were only introduced at the beginning of this century. Hardness is the resistance offered by material to indentation made, depends upon the applied load, the sharpness of the indenter and the time for which the applied load is maintained. Table 4 and Figure 5shows the type of indenter, load, dial numerical used for hardness test

Table 4. Hardness parameters used for the mechanical test of the specimen

\begin{tabular}{|c|c|c|c|}
\hline Scale & Indenter & Load (kgf) & $\begin{array}{c}\text { Dial } \\
\text { numerical }\end{array}$ \\
\hline A & Diamond cone & 60 & Black \\
\hline B & $1 / 16$ " ball & 100 & Red \\
\hline C & Diamond cone & $10-150$ & Black \\
\hline
\end{tabular}

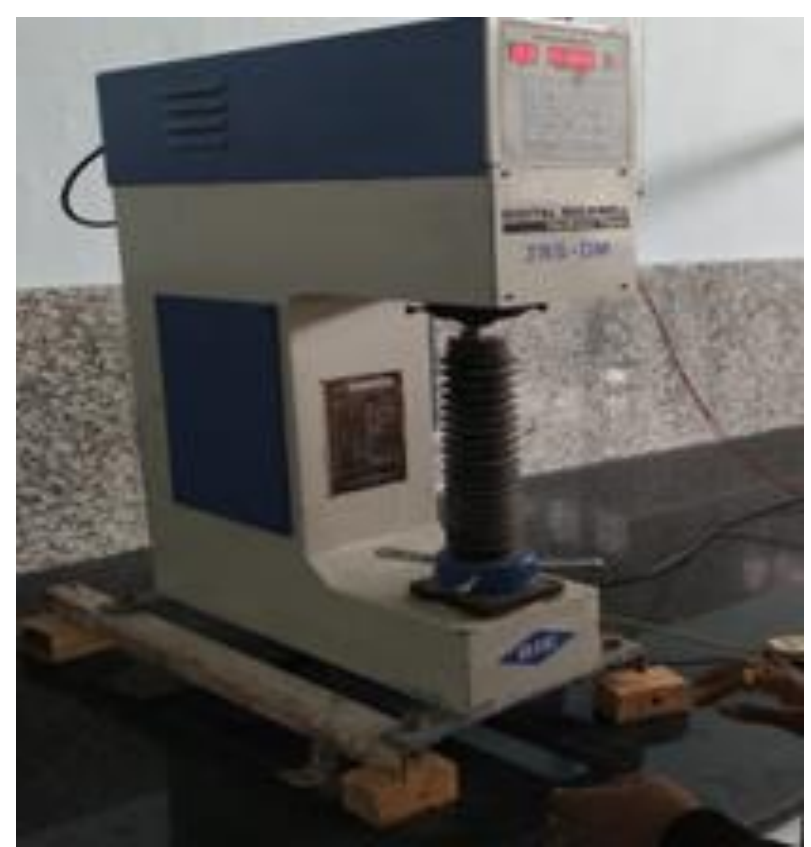

Figure 5. Rockwell hardness test machine 


\subsection{SEM Observation}

The microstructure was observed under an optical microscope at 100X magnification and microphotographs were taken. Surface modification was useful for high-resolution SEM observation which was used for the present research. A good balance between toughness and hardness in the casting can be achieved by refining the microstructure of the specimen.

\section{Results and Discussion}

\subsection{Tensile Test Result}

From the Table 5, it is observed with the rise in the amount of molybdenum both tensile strength and hardness increases, initially sharply and later slowly. It indicates that once matrix becomes fully pearlite, further increase in molybdenum content shows weaker effect.

Table 5. Effect of molybdenum on the tensile strength

\begin{tabular}{|c|c|c|c|}
\hline SAMPLE & C/S area $\left(\mathrm{mm}^{2}\right)$ & $\mathrm{UTS}(\mathrm{Kgf})$ & $\mathrm{UTS}_{0}(\mathrm{MPa})$ \\
\hline $\begin{array}{c}\text { Class } 30 \\
\text { GCI }\end{array}$ & 113.04 & 1875 & 162.63 \\
\hline $4 \mathrm{gm} \mathrm{Mo}$ & 113.04 & 1720 & 149.20 \\
\hline $30 \mathrm{gm} \mathrm{Mo}$ & 113.04 & 1685 & 146.15 \\
\hline $60 \mathrm{gm} \mathrm{Mo}$ & 113.04 & 1610 & 139.65 \\
\hline $120 \mathrm{gm} \mathrm{Mo}$ & 113.04 & 1990 & 172.61 \\
\hline $150 \mathrm{gm} \mathrm{Mo}$ & 113.04 & 1925 & 166.97 \\
\hline
\end{tabular}

However, in present case study grey cast iron was used as the base metal, while varying molybdenumup to $0.75 \%$ where significant effects are seen. The figure 6 below shows the specimens used for the tests. The maximum UTS of $172.61 \mathrm{MPa}$ was obtained from the specimen with 120 gm molybdenum and least tensile strength of $139.65 \mathrm{MPa}$ was observed in the specimen fabricated with $60 \mathrm{gm}$ molybdenum.

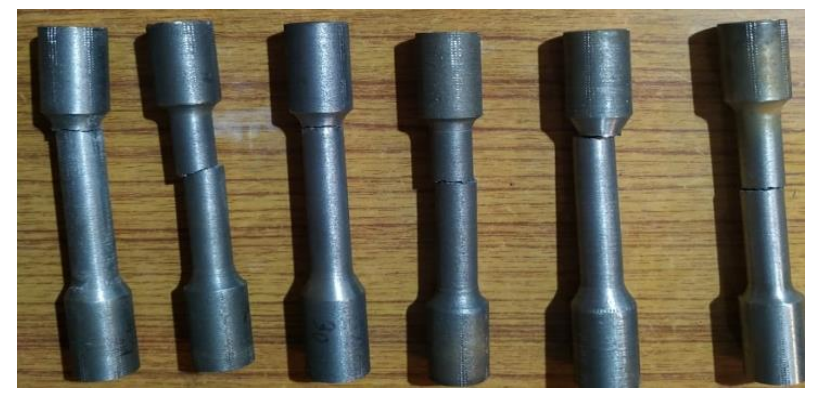

Figure 6. Tensile bar after tensile testing procedure

\subsection{Hardness Test Result}

The average hardness values of both molybdenum and As-cast alloy samples after austempering are presented in the Table 6 and Figure 7 below. Apparently, after austempering temperature the hardness of each class of grey cast iron increased for all samples. The hardness of type 1 alloy with different proportion of molybdenum addition to grey cast iron was $27 \mathrm{HRB}, 26.4 \mathrm{HRB}$, 24.6HRB, $28 \mathrm{HRB}, 29.3 \mathrm{HRB}$, when it comes to type 2 the hardness values are $25 \mathrm{HRB}, 22.8 \mathrm{HRB}, 18.8 \mathrm{HRB}$, 38.2 HRB, 25.2 HRB and type 3 are $24.2 \mathrm{HRB}, 30.3 \mathrm{HRB}$, 23.9 HRB, 26.6 HRB, 26.1 HRB, the average difference in percentage in each type of sample is about 5 to $10 \%$. The Table 6 below shows the three sample tests mean values after the hardness test.

Table 6. Effect of Molybdenum addition on the hardness

\begin{tabular}{|c|c|c|c|c|}
\hline Types & $\mathbf{1}$ & $\mathbf{2}$ & $\mathbf{3}$ & Average $\left(\mathbf{R}_{\mathbf{c}}\right)$ \\
\hline Class 30 (GCI) & 29.6 & 32.0 & 26.2 & 29.26 \\
\hline $\mathbf{4}$ gm Mo & 27.9 & 25.0 & 24.2 & 25.70 \\
\hline 30 gm Mo & 26.4 & 22.8 & 30.3 & 26.50 \\
\hline 60 gm Mo & 24.6 & 18.8 & 23.9 & 22.43 \\
\hline 120 gm Mo & 28.0 & 38.2 & 26.6 & 30.93 \\
\hline 150 gm Mo & 29.3 & 25.2 & 26.1 & 26.86 \\
\hline
\end{tabular}




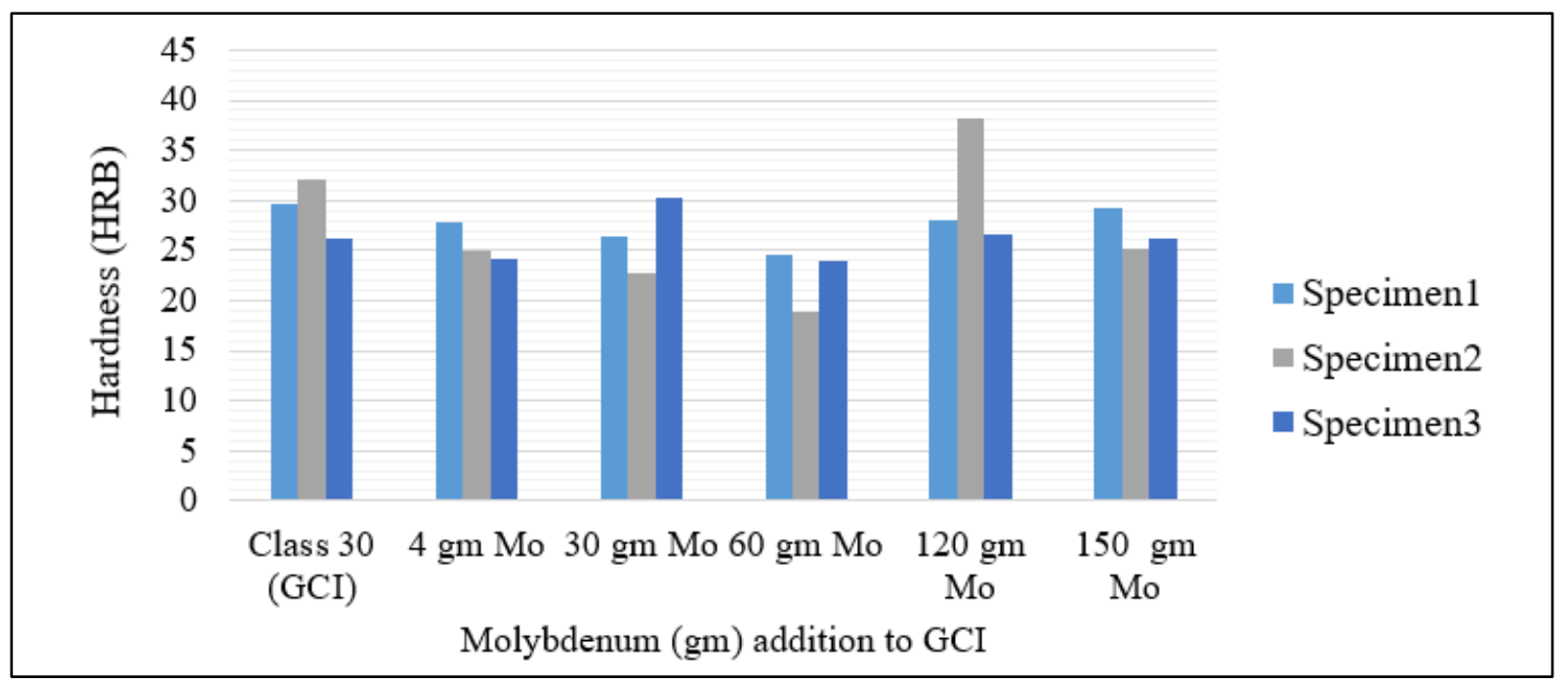

Figure 7. Graphical representation of the overall hardness vs added molybeduem to GCI of various specimens used in the test.

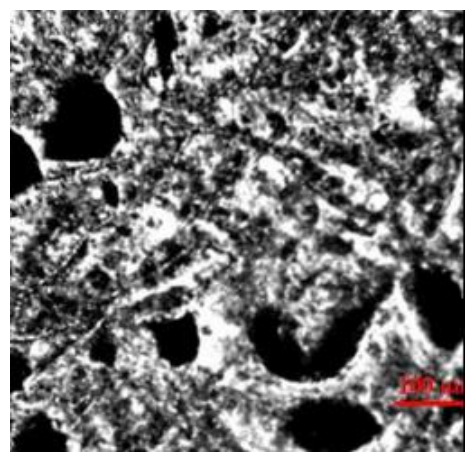

Base Metal i.e. $0 \%$ Mo ( $100 \mathrm{X}$ )

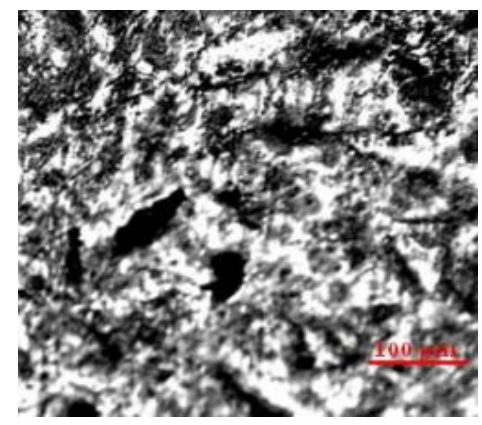

Specimen 3 i.e. $0.15 \%$ Mo ( $100 \mathrm{X})$

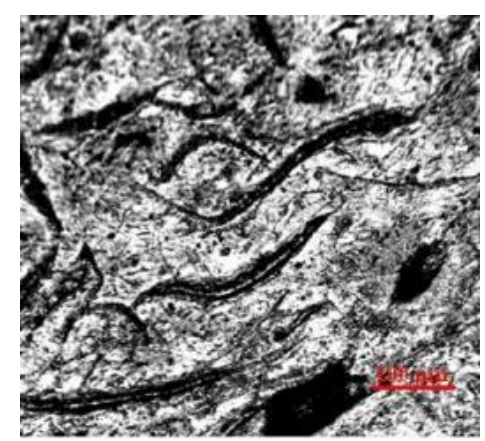

Specimen 5 i.e. $.55 \% \mathrm{Mo}(100 \mathrm{X})$

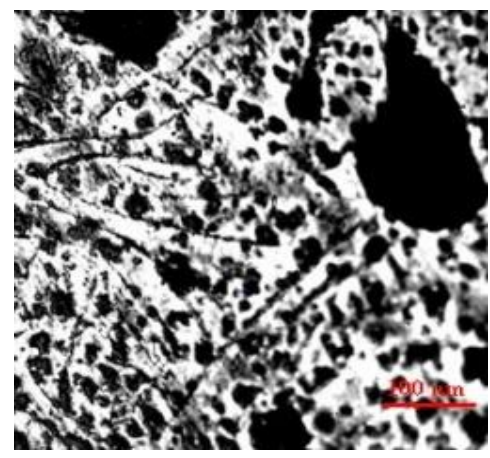

Specimen 2 i.e. $0.02 \%$ Mo (100X)

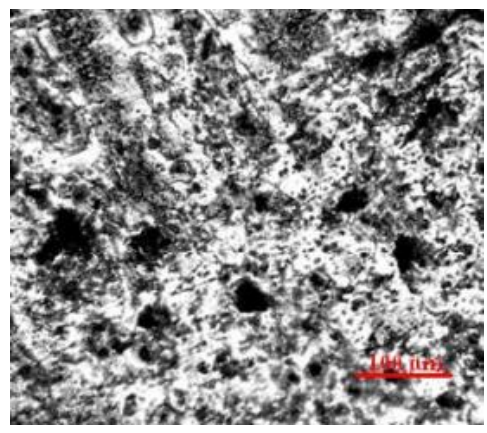

Specimen 4 i.e. $0.27 \%$ Mo ( $100 \mathrm{X})$

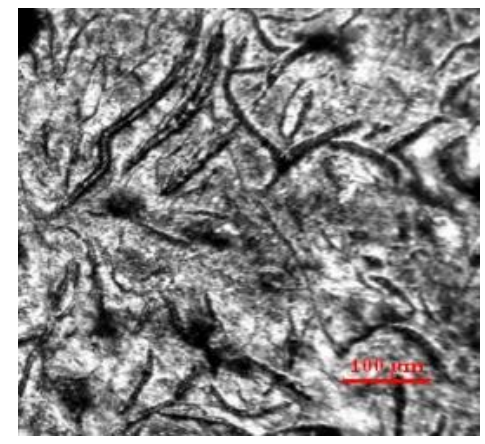

Specimen 6 i.e. $0.75 \%$ Mo ( $100 \mathrm{X})$

Figure 8. SEM images of the graphite distribution for grey cast iron and base iron 


\subsection{SEM Analysis}

Figure 8 shows the graphite diffusion of grey cast iron and base iron with an increase in the molybdenum and keeping grey cast iron content at a fixed rate used as per industry standards, while Figure 8 shows the graphite distribution for the grey cast iron with a rise in the molybdenum, keeping molybdenum percentage to $2.2 \%$ fixed, the number of graphite flake is increased and the size of the graphite flake is reduced due to the graphitization tendency of the molybdenum. All photomicrographs show refinement in pearlite with molybdenum inclusion.

\section{Conclusions}

In view of the overhead discussion, the following conclusions are stated:

1. Molybdenum inclusion guide to molybdenum weeny segregation with addition to carbides precipitation in the grey cast iron, molybdenum addition can produce chemical in homogeneity and thus irregular graphite flake distribution in the alloys.

2. Molybdenum addition can reduce the thermal expansion coefficient. Lower molybdenum inclusion refines the majority of graphite flakes but increases the length of a small fraction of graphite flakes and consequently improves the thermal conductivity, while higher molybdenum inclusion give rise to precipitation and solution strengthening thus enhances the ultimate tensile strength.

3. Adequate molybdenum addition is a successful way to enlarge HPCI with enhanced mechanical properties and adjusted thermal conductivity. Average difference in percentage of hardness in each type of moylbdenum sample is about 5 to $10 \%$.

4. Finer grained structures possess excessive hardness and less toughness. Coarsened grained compositions have less hardness and more ductility with better toughness.

\section{Acknowledgement}

I would like to thank the Department of Automobile Engineering, Vignan University, Vadlamudi for having been a source of constant inspiration, precious guidance and generous assistance during the project work. We deem it as privilege to have worked under his able guidance. Without his close monitoring and valuable suggestions this work wouldn't have taken this shape. We feel that his help is un-substitutable and unforgettable

\section{REFERENCES}

[1] Xianfei Ding, Xiaozheng Li, Hong Huang, Warkentin Matthias, Shiyao Huang, Qiang Feng. "Effect of Mo addition on as-cast microstructures and properties of grey cast irons", Materials Science and Engineering: A, 2018

[2] Rosenthal, "Theory of metal casting”, TMH Co. Ltd., 1990, pp 23,607.

[3] Walter, "Iron Castings Hand Book", Iron Castings Society", INCO, pp 21, 146, 206, 208

[4] Cupola Hand Book, 5th Edition, AFS Publications, pp 365-378.

[5] Molybdenum Steels Irons Alloys, Climax Molybdenum Company, pp 15-16, 42, 52, 288-304.

[6] Vanmaldegiam M. D. and Rundman K. B., "On the structure and properties of Austempered Gray Cast Iron", AFS Transactions, 1986, Vol.94, pp 249-254.

[7] Kovacs B. V., Keough J. R., "physical properties and Application of Austempered Gray Iron", AFS Transcation, 1993, Vol.101, pp 283- 291.

[8] Heat Treaters Guide, Standard Practices and Procedures for steel, American Society for Metals, 1982.

[9] Angus H. T., Cast Iron: Physical and Engineering Properties, Butterworths, Second Edition, 1976.

[10] Casting, A.S.M Hand Book Edition 9, Vol- 15, Pg629-646.

[11] Janowak and Gundlach, "A Modern Approach to alloying gray Iron”, AFS, Vol.90, 1982, pp 847-862.

[12] Hungrymen K. L., A.F.S Transaction 1998, pp 665-671.

[13] VanamaldegianM.D and Rundman K.B., on the structure and properties of Austemperd Gray cast Iron".AFS Transcation, 1986, vol.94, Page-249-254.

[14] D.F.Krause, "Grey iron A unique enginneringmaterail" Grey, Ductile, and Malleable Iron Castings Current Capabilities, ASTM STP455, Americak society of Tesying and Materials, Philadelpia, 1969, pp.3-28.

[15] Behera, G. \& Sohala, S. R. (2012). Effect of copper on the properties of austempered ductile iron castings. Bachelor thesis. Department of Metallurgical and Materials Engineering, National Institute of Technology, Rourkela, India.

[16] BIS IS 2078: 1979, Method for tensile testing of gray cast iron, Sai Global. 